\title{
Attitudes of Libyan Patients towards the Use of Rubber Dam in Endodontic Treatment in Benghazi
}

\author{
Ibtesam Orafi ${ }^{1, *}$, Mohammad Hammad ${ }^{2}$ \\ ${ }^{1}$ Department of Conservative Dentistry and Endodontics, School of Dentistry, The University of Benghazi, Benghazi, Libya \\ ${ }^{2}$ Conservative Dentistry Department, School of Dentistry, The University of Jordan, Amman, Jordan
}

Copyright $\bigcirc 2018$ by authors, all rights reserved. Authors agree that this article remains permanently open access under the terms of the Creative Commons Attribution License 4.0 International License

\begin{abstract}
Aims: this study investigated the attitudes of adult patients in Benghazi towards the use of rubber dam (RD) and evaluated time needed for rubber dam application and duration of use. Methodology: A self-administrated questionnaire was designed and distributed to 200 patients receiving endodontic treatment by: (a) General Dental Practitioners (GDPs) (b) Endodontists. Patients were kindly requested to fill the questionnaire directly after the treatment. Data were entered into a database and subsequently analyzed using SPSS. Results: The majority of patients $(77 \%$ and $70 \%)$ whom were treated by endodontists and GDPs respectively reported they would prefer RD to be used at their next appointment, and most had a positive attitude of the experience. A statistically significant association between age and gender was found among the GDPs' patients $(P<0.05) .87 .9 \%$ and $65.6 \%$ of patients whom were treated by endodontists and GPDs respectively reported that the operators sufficiently explained the purpose of rubber dam to them, a statistically significant difference between the two groups of patients $(P<0.001)$ was reported. The mean time needed for rubber dam placement was 4.28 min for GDPs and 1.10 minutes for endodontists, which was statistically significant. A significant difference between the two groups of patients with regards to their opinions toward the benefit of using the rubber dam was noticed $(P<0.05)$. Prolonged RD use exhibited association with a negative opinion of the experience of RD. Conclusions: Patients generally showed a positive attitude towards the RD. Moreover, some patients showed a negative attitude because of time taken by inexperienced operator in placement of rubber dam.
\end{abstract}

Keywords Questionnaire, Patient Attitude, Rubber Dam, Endodontists, Practioners

\section{Introduction}

Ideal endodontic practice necessitates the use of isolation techniques. A well-established method is the use of a rubber dam. Rubber dam was first introduced in the 1860 s by S.C. Barnum [1] and has since been used in dental practices. The application of a rubber dam has many advantages such as providing the practitioner with a dry operative field, improves visibility, minimizes patient conversation, consequently increasing the overall efficacy of the treatment [2].

Rubber dam is universally taught and recommended by professional organizations [3-6]. The European Society of Endodontology [7] highlighted the importance of using rubber dam in endodontic treatment for the benefits of both operator and patient. In all dental schools in the UK, the use of rubber dam is mandatory when students undertake root-canal treatment. The American Association of Endodontics stressed on using of rubber dam (RD) as an integral and essential part of any non-surgical endodontic treatment [4]. Similarly, the Australian Dental Association recommended the use of $\mathrm{RD}$ for restorative work to reduce exposure of dental practitioners and clinical support staff to potentially infected aerosols [6].

In spite of many advantages of $\mathrm{RD}$ use and the recommendations, the literature suggested that the rubber dam is not used routinely by dental practitioners for root canal treatment [8-13]. Surprisingly, few studies showed a high percentage of rubber dam application among dental practitioners; $90 \%$ in Sweden [14] and $60 \%$ in the USA [15].

Many reasons have been cited for not using $\mathrm{RD}$, including concerns over patient acceptance, time required for application, cost of equipment and materials, insufficient training, difficulty in use and low treatment fees [16-20]. These attitudes clarify why there is a significant discordance between the presumed standard of care and actual practice [21]. However, there are gaps in the literature on the relationship between provider (the operator) and their training with patients' attitude toward acceptance of RD. Conversely, other studies disagreed with their claim and reported a positive attitude of patients toward the use of rubber dam [22-25]. Recently, in 
Benghazi Dental School, the rubber dam is encouraged to be mandatory in endodontic treatment. The later regulation was applied mandatory in all UK dental school [23]. Literature searches reported a limited number of studies, which look at the attitude of patients towards the use of rubber dam, and no study was carried out in Libya.

\section{The aims of the present study were:}

1. To objectively investigate the attitude of Libyan adult patients toward the use of rubber dam in endodontic treatment.

2. To investigate the effect of some personal and clinical factors on patient's views.

3. To evaluate the mean time needed for rubber dam application and the duration of its use.

\section{Materials and Methods}

The study was conducted at dental private clinics in the city of Benghazi from September 2017 to May 2018.

The questionnaire was designed based on questionnaires used in similar studies by different authors [23, 26-29]. The questionnaire was translated to Arabic language and back to English by two independent professional translators to avoid any translation errors. The questionnaire also has been also validated by a pilot study of 10 patients for its clarity and if there was any amendment to be done.

The self-administrated questionnaire was handed to 200 patients following their endodontic treatment sessions, which was performed under the use of rubber dam. The survey was performed for two groups of patients divided according to the category of operator. Each group comprised of 100 patients: adult patients who were receiving dental treatment under $\mathrm{RD}$ from, (a) Endodontists in private dental practice (b) General Dental Practitioners in private dental practice. The goal was to allow an evaluation to be made regarding the effect of the operator's experience on the patient's opinions concerning $\mathrm{RD}$.

The questionnaire (Figure 1) is made of two parts: First part to be filled by the patient who constitutes of 12 questions which enquired the following data from patients; patient's demographic data, any previous rubber dam placement experience, the current experience and problems associated with the application of rubber dam.

After the end of the treatment, the questionnaire was handed to the patient. Patients who were willing to participate in the study filled in the questionnaires in the waiting room after the treatment had been done to avoid the influence of the operator on their answers. The patients could refuse to fill in the questionnaires. Patients were assured the confidentiality of their response.

The second part was filled by the operator's dental assistant, whom kindly recorded the time needed for applying and removing the rubber dam: The time of rubber dam placement and removal were measured using a stopwatch. The placement time was measured from the beginning to the end of application. The time of removal was measured from the finishing of rubber dam application to its removal. These times were noted on the questionnaire together with information about the category of operator (general dental practitioner or endodontists).

Data from the completed questionnaires were entered into a database and subsequently analysed using the Statistical Package for the Social Sciences (SPSS), version 21.

\section{To be filled with patient}

1. Patient's age

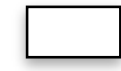

2. Patient sex:

M

3. Have you had rubber dam placed before for endodontic treatment?

Yes

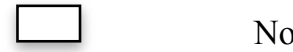

No

If yes, when it was placed?

Was it is applied by

Same dentist

Different dentist
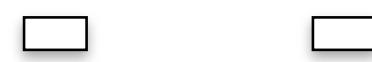

4. Did you find today's experience?

Pleasant

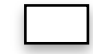

Comfortable

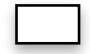

Students

Uncomfortable

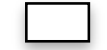

Painful

5. Any complication during its placement. 
Yes

No

6. Did the d $\square$ explain why the rubber $\square$ was being placed?

Yes NO

7. Was the explanation clear to you? Yes NO

8. Did you feel that it was being used

For your benefit

The dentist benefit Both

9. Have you had a local anaesthesia before placement of rubber dam?

Yes

No

10. Would you prefer rubber dam to be used next time?

Yes No No preference

11. What bothered you during treatment with rubber dam? More than one answer is possible. Please tick the right answer(s):

$\bigcirc$ Difficulty swallowing or breathing.

Placement of rubber dam took too long.

Impossibility of rinsing mouth during treatment.

Impossibility of communicating with operator during treatment.

Pain caused by rubber dam.

Other. Indicate

12. What do you consider to be a benefit of using rubber dam? More than one answer possible. Please tick the right answer(s),

No accumulation of water in mouth.

No irritation of the mouth by solutions used.

No risk of swallowing or inhalation of foreign bodies.

Increase in the quality of treatment performed.

$\bigcirc$ Decrease in infection transmission.

Other. Indicate

Please add any comments you have for/against your experience of rubber dam.

\section{To be filled by GDPs/ Endodontist's assistant:}

Operator: GDPs Endodontist

Procedure

Time taken to apply rubber dam

Minutes

Duration of rubber dam use

Minutes

Figure 1. Questionnaire used to gather information. 


\section{Results}

\section{Response rate}

Endodontists' patients Group (ED): Out of 100 patients targeted, rubber dam was applied to 99 of them. One patient could not tolerate the rubber dam. He reported episodes of difficulty of breathing. Response rate was $99 \%$.

General Dental Practitioners' patients Group (GDPs): Before the target of 100 was achieved, 7 forms were discarded, four of which had not been fully completed by the patient, and two had not had the timings to complete all the questions and one patient left the questionnaire totally empty. Response rate was $93 \%$.

\section{Age and gender}

Respondents were grouped into three age groups, (a) 40 years and below, (b) 41- 60 years and (c) above 60 years. The numbers of respondents in each category for each patient group were:

Group ED: (a) 39 (25 females, 14 males); (b) 51 (32 females, 19 males); (c) 9 (5 females, 4 males).

Group GDPs: (a) 24 (13 females, 11 males); (b) 43 (29 females, 14 males); (c) 26 (14 females, 12 males).

There was no statistically significant difference between age and sex among the patients whom were treated by endodontists $(P>0.05)$ [Figure 2]. Conversely, there was a statistically significant difference among patients whom were treated by the GDPs $P=0.02$ [Figure 3].

The majority of patients reported that they did not have any previous experience with regards to the use of rubber dam. There was no significant difference between the two groups of patient $(P>0.05 \%)$.

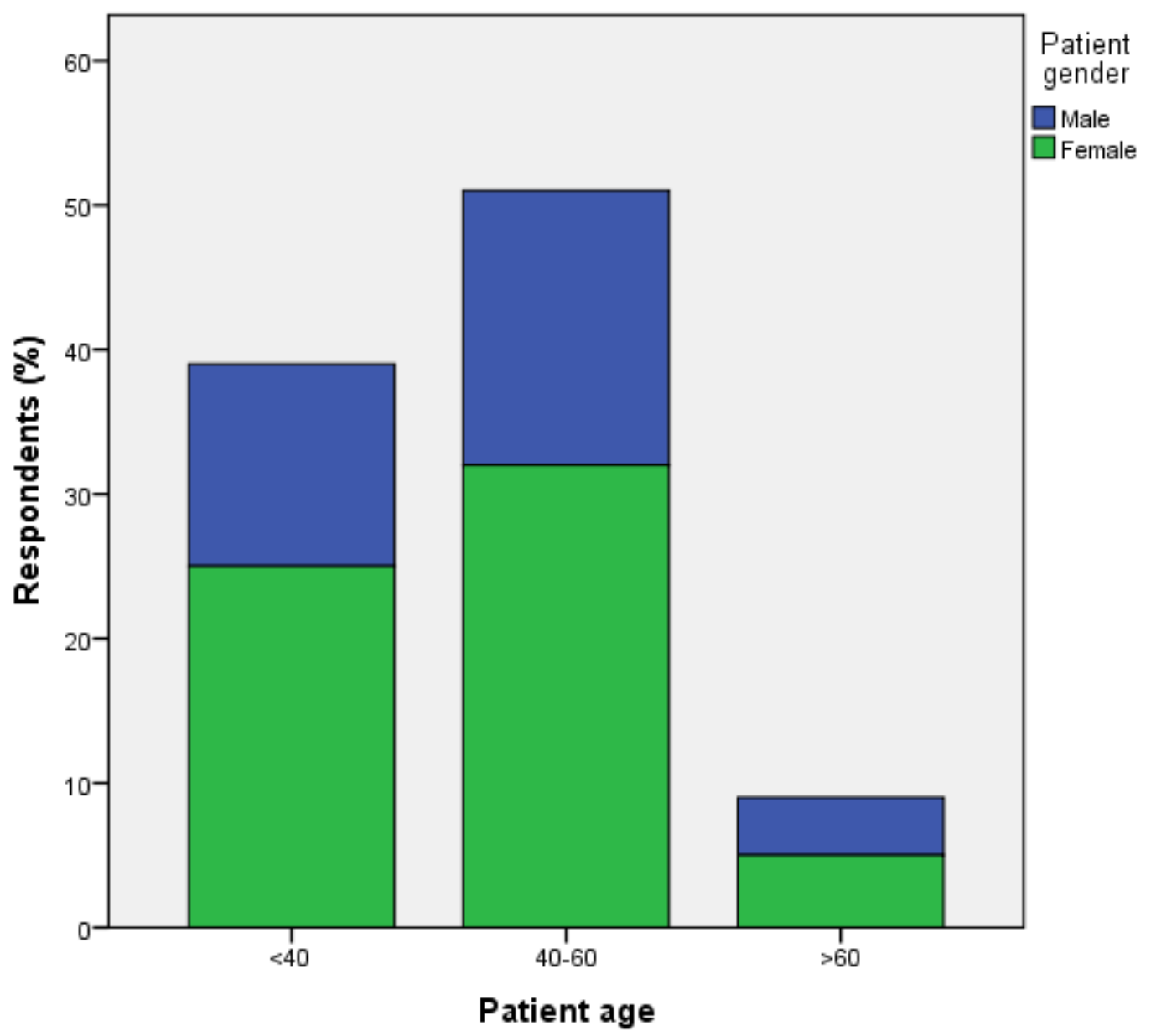

Figure 2. The distribution of Endodontists patients' by age and gender is shown. 


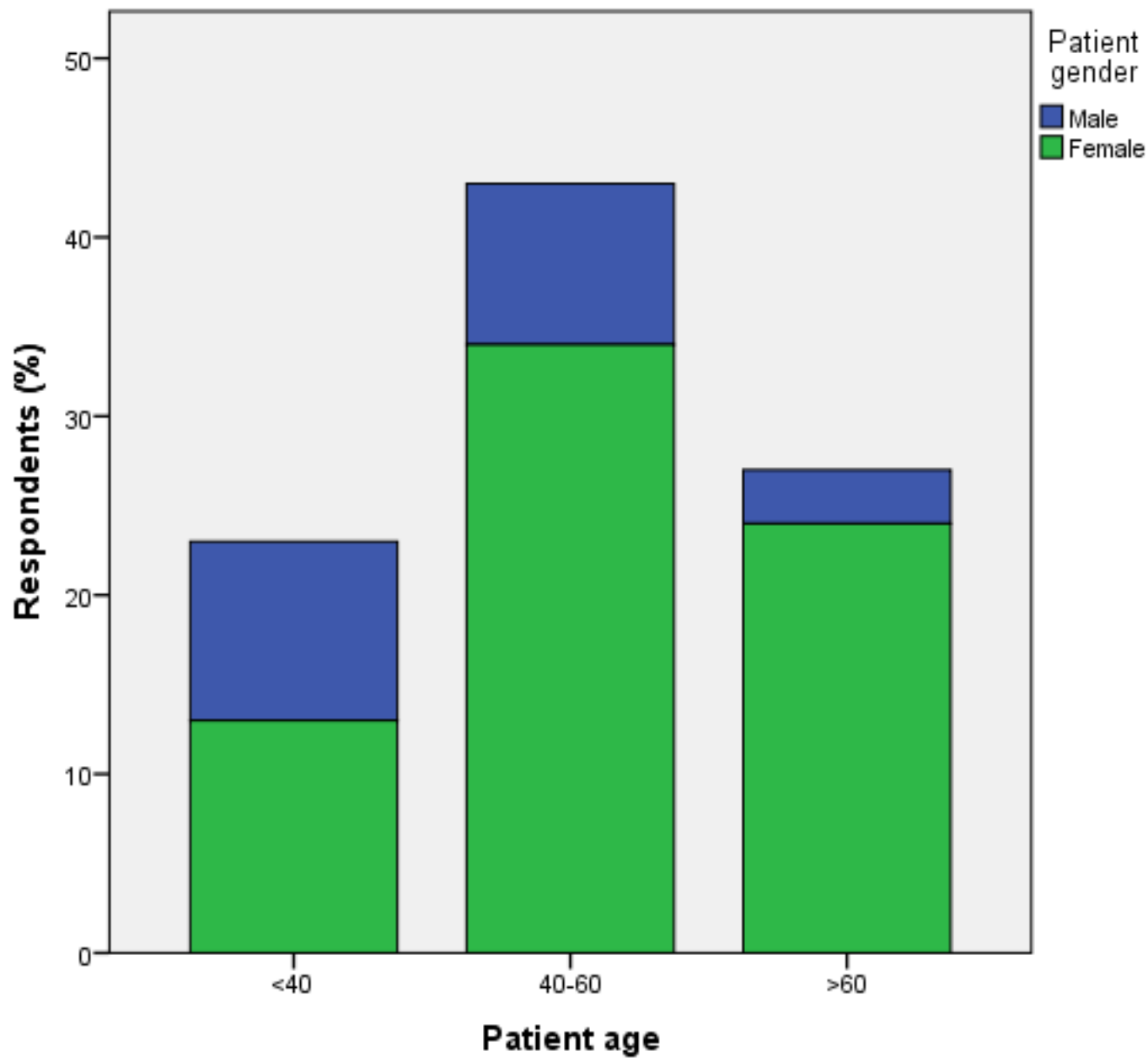

Figure 3. The distribution of GDPs patients' by age and gender is shown.

Patients' previous experience with regards to the use of rubber dam:

The majority of the patients whom were treated before either by endodontists or GDPs reported no previous experience of the use of rubber dam (Table 1). There was no significant difference between both groups of treated patients $P=0.093$.

Table 1. Numbers of patients who reported the previous use/ non-use of the RD.

\begin{tabular}{|c|c|c|c|}
\hline Participants & Yes (no.) & No (no.) & Total \\
\hline ED patients & 21 & 78 & 99 \\
\hline GDPs patients & 13 & 80 & 93 \\
\hline Total & 34 & 158 & 192 \\
\hline
\end{tabular}

The majority of endodontists (81\%) and GDPs (79\%) patients reported that their previous experience was performed by the same operators. There was no significant difference between endodontists and GDPs patient $(P>0.05)$.

\section{Current study experience:}

Patients ranked their current experience of RD as either
(I) pleasant, (II) comfortable, (III) uncomfortable or (IV) painful.

ED group: $6(6 \%)$ found their current experience of RD pleasant, $86(86.8 \%)$ comfortable, 7(7\%) uncomfortable, and none felt pain while using the RD.

GDPs group: 4 (4.3\%) found RD pleasant, 67(73\%) comfortable, whilst, $21(22 \%)$ felt it was uncomfortable and 1 found it painful [Figure 4].

There was a significant difference between the endodontists and GDPs with regards to the rubber dam experience at the time of conducting this study $(\mathrm{P}<0.05)$.

\section{Patients' preferences towards the use of rubber dam at their next appointment:}

When participants were asked whether they would prefer $\mathrm{RD}$ to be used at their next appointment, the responses of the patients whom were treated by endodontists were as following: (76) $76.9 \%$ said yes, 12 $(12 \%)$ said no and 11 patients showed no preference. Similarly, when the GDPs group were asked whether they would prefer RD to be used at their next appointment, 65 $(70 \%)$ said yes, $9(10 \%)$ said no, with 19 patients expressing no preference [Figure 5]. 


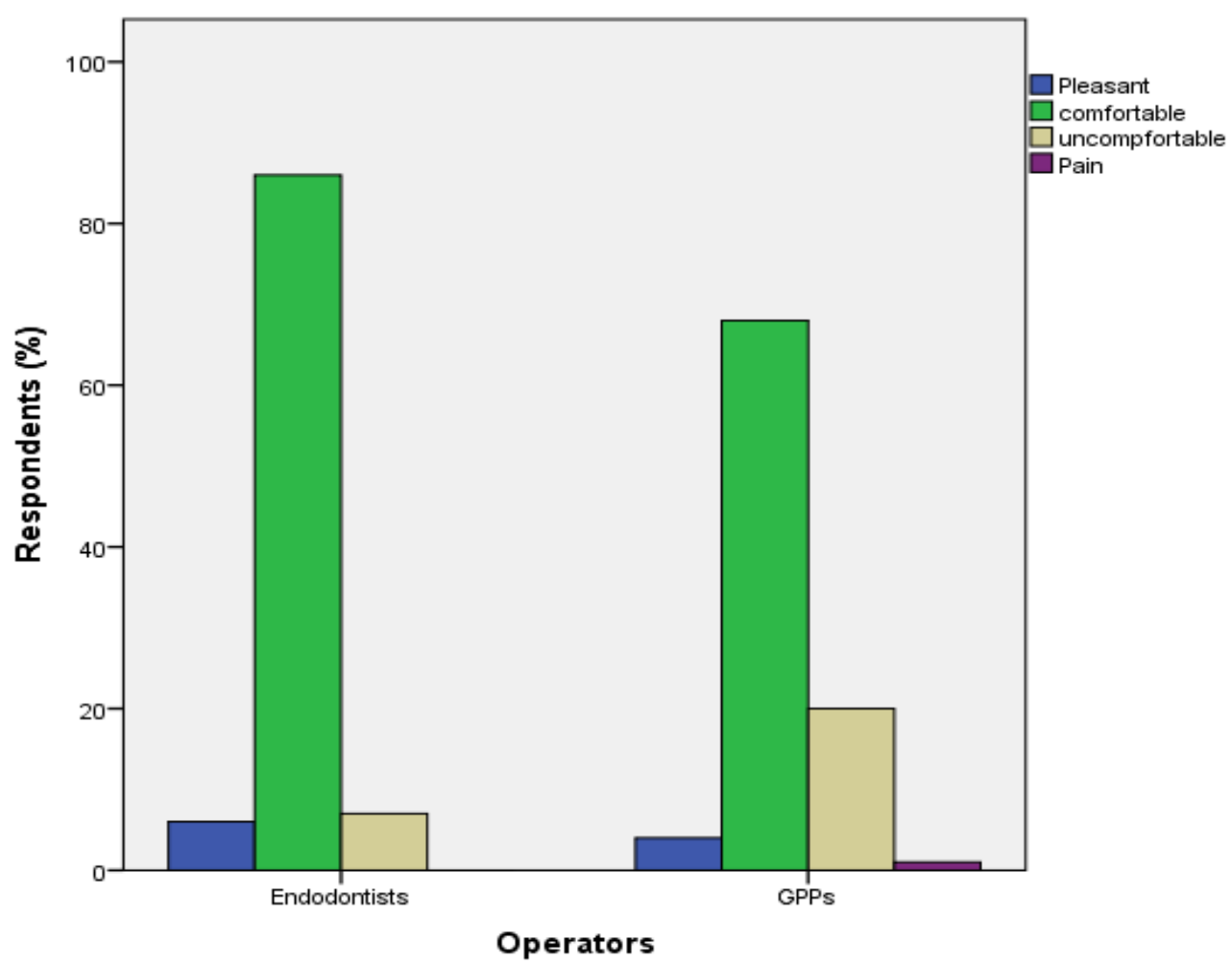

Figure 4. Illustration of the respondent's view towards the current use of rubber dam in both groups.

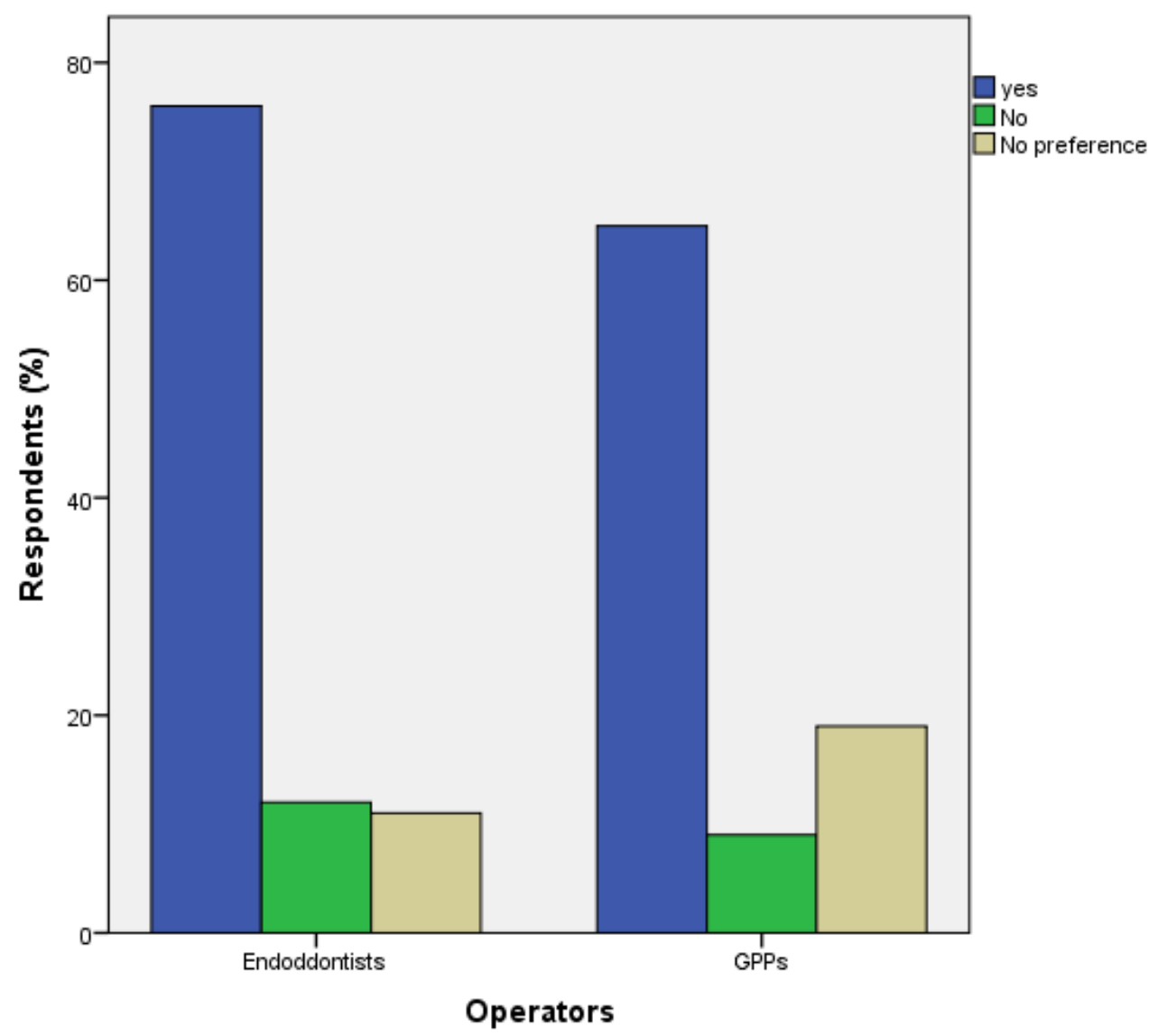

Figure 5. Respondent's view towards their future preferences towards the use of rubber dam. 
Chi square test shows a high significant difference between both groups in either their current experience in using the rubber dam and even the future preference to use rubber dam $(P<0.05)$.

\section{Explanation for the reason of using rubber dam by the operators}

A total of $87.9 \%(\mathrm{n}=87)$ and $65.6 \%(\mathrm{n}=61)$ patients whom were treated by endodontists and GPDs respectively and filled in the questionnaire reported that the operators sufficiently explained the purpose of use of rubber dam to them. There was a statistically significant difference between the two groups of patients $(P<0.001)$

There was a positive correlation between the attitudes of patients in either groups towards the use of rubber dam and the explanation by operator $(\mathrm{P}<0.05)$.

\section{Complication during use:}

None of the patients in both groups reported any complications during the application of rubber dam. No significant difference between the two groups of patients was found $(P>0.05)$

\section{Administration of local anesthesia:}

The majority of the patients whom were treated by endodontists ( $82 \%$ ) and more than half of patients $(58 \%)$ whom were treated by GDPs reported the administration of local anesthesia prior to their endodontic treatment. There is a significant difference between both group of patients with regards to the administration of local anesthesia prior to the endodontic treatment $(P=0.003)$.

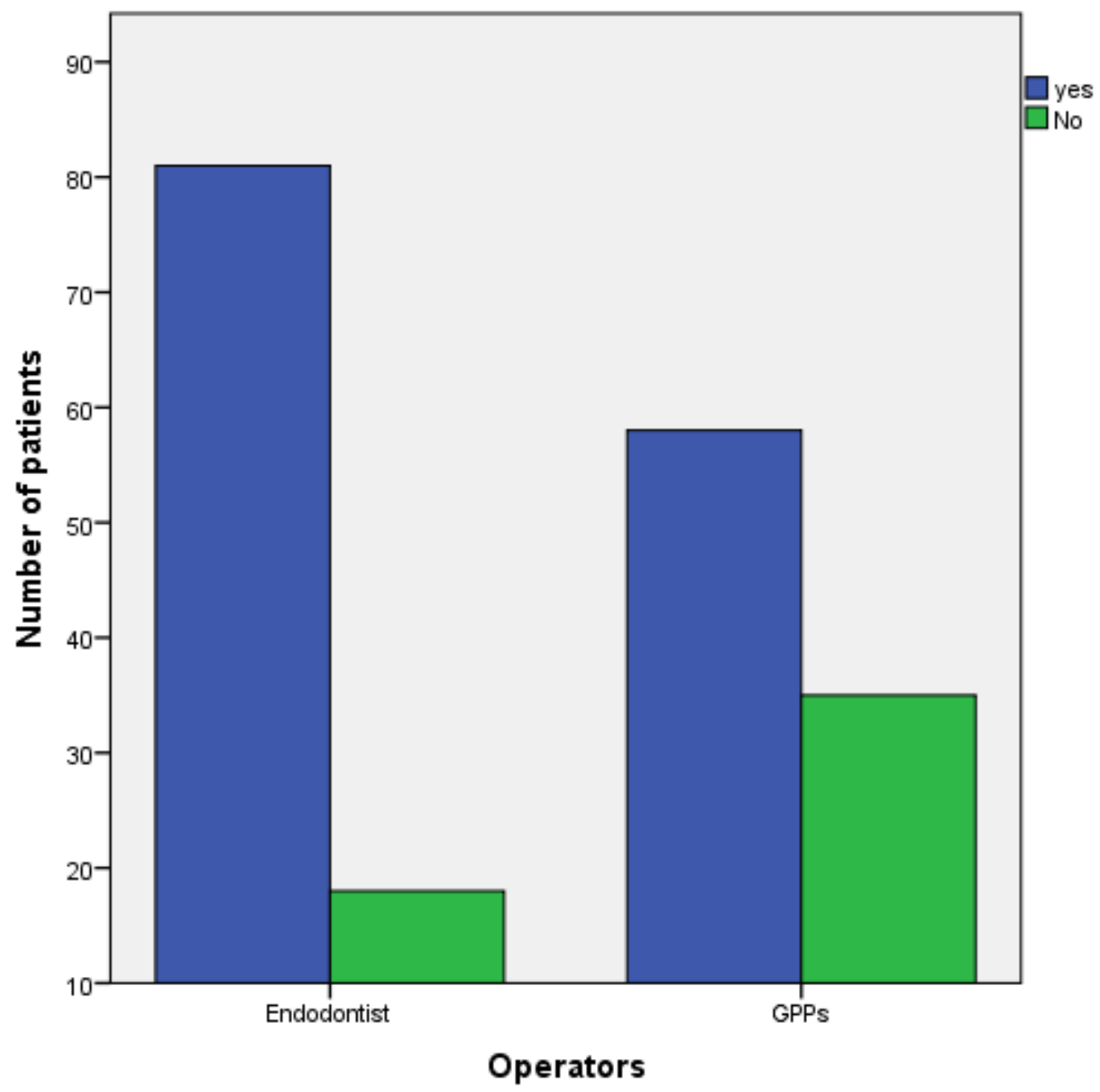

Figure 6. Number of patients who reported the administration of LA by either group of operators. 
The benefit of using rubber dam: Number of participant's views towards their opinion about the benefit of using RD is illustrated in table 2. Chi square test shows a significant difference between the two groups of patients with regards to their opinion towards the benefit of using rubber dam $P<0.05$.

Table 2. Illustrate the respondents view toward the benefit of using rubber dam

\begin{tabular}{|c|c|c|c|c|}
\hline Participants & $\begin{array}{c}\text { Your } \\
\text { benefits }\end{array}$ & $\begin{array}{c}\text { Dentist } \\
\text { benefit }\end{array}$ & Both & Total \\
\hline ED patients & 85 & 3 & 11 & 99 \\
\hline GDPs patients & 63 & 11 & 19 & 93 \\
\hline Total & 148 & 14 & 30 & 192 \\
\hline
\end{tabular}

Answer to the questions "what bother you during treatment with rubber dam" and what do you consider to be the benefit of rubber dam? are summarized in table 3 and 4 Both questions accept more than one answer. There was no significant difference between the two groups of patients $P>$ 0.05 .

Table 3. Respondents negative view from using the rubber dam.

\begin{tabular}{|l|c|c|c|}
\hline $\begin{array}{l}\text { What bother you during } \\
\text { treatment with rubber dam? }\end{array}$ & $\begin{array}{c}\text { ED } \\
\text { patients } \\
\mathrm{N} \mathrm{( \% )}\end{array}$ & $\begin{array}{c}\text { GDPs } \\
\text { patients } \\
\mathrm{N}(\%)\end{array}$ & $\begin{array}{c}\text { Total } \\
\mathrm{N} \\
(\%)\end{array}$ \\
\hline $\begin{array}{l}\text { Impossibility of rinsing mouth } \\
\text { during treatment. }\end{array}$ & $\begin{array}{c}19 \\
(19 \%)\end{array}$ & $\begin{array}{c}22 \\
(24 \%)\end{array}$ & $\begin{array}{c}41 \\
(21 \% \\
)\end{array}$ \\
\hline $\begin{array}{l}\text { Placement of rubber dam took too } \\
\text { long. }\end{array}$ & $5(5 \%)$ & $3(3 \%)$ & $\begin{array}{c}8 \\
(4 \%)\end{array}$ \\
\hline $\begin{array}{l}\text { Difficulty swallowing or } \\
\text { breathing. }\end{array}$ & $\begin{array}{c}34 \\
(34 \%)\end{array}$ & $\begin{array}{c}41 \\
(44 \%)\end{array}$ & $\begin{array}{c}85 \\
(44 \% \\
)\end{array}$ \\
\hline $\begin{array}{l}\text { Impossibility of communicating } \\
\text { with operator during treatment. }\end{array}$ & $\begin{array}{c}58 \\
(59 \%)\end{array}$ & $\begin{array}{c}69 \\
(74 \%)\end{array}$ & $\begin{array}{c}127 \\
(66 \% \\
)\end{array}$ \\
\hline Pain caused by rubber dam & $5(5 \%)$ & $3(3 \%)$ & $\begin{array}{c}8 \\
(4 \%)\end{array}$ \\
\hline
\end{tabular}

Note more than one answer was allowed.

Table 4. Respondents positive view from using the rubber dam.

\begin{tabular}{|l|c|c|c|}
\hline $\begin{array}{l}\text { What do you consider the } \\
\text { Benefit of rubber dam? }\end{array}$ & $\begin{array}{c}\text { ED } \\
\text { patients } \\
\mathrm{N}(\%)\end{array}$ & $\begin{array}{c}\text { GDPs } \\
\text { patients } \\
\mathrm{N}(\%)\end{array}$ & $\begin{array}{c}\text { Total } \\
\mathrm{N}(\%)\end{array}$ \\
\hline $\begin{array}{l}\text { No accumulation of water in } \\
\text { mouth. }\end{array}$ & $59(60 \%)$ & $41(44 \%)$ & $\begin{array}{c}100 \\
(52 \%)\end{array}$ \\
\hline $\begin{array}{l}\text { No irritation of the mouth by } \\
\text { solutions used. }\end{array}$ & $68(86 \%)$ & $56(60 \%)$ & $\begin{array}{c}124 \\
(64 \%)\end{array}$ \\
\hline $\begin{array}{l}\text { No risk of swallowing or } \\
\text { inhalation of foreign bodies. }\end{array}$ & $76(76 \%)$ & $80(86 \%)$ & $\begin{array}{c}156 \\
(81 \%)\end{array}$ \\
\hline $\begin{array}{l}\text { Increase in the quality of } \\
\text { treatment performed. }\end{array}$ & $69(69 \%)$ & $71(75 \%)$ & $\begin{array}{c}140 \\
(73 \%)\end{array}$ \\
\hline $\begin{array}{l}\text { Decrease in infection } \\
\text { transmission. }\end{array}$ & $55(55 \%)$ & $39(42 \%)$ & $\begin{array}{c}94 \\
(49 \%)\end{array}$ \\
\hline
\end{tabular}

Note more than one answer was allowed.

Time taken and the duration of using the rubber dam:

The time needed for the application and duration of rubber dam placed in the oral cavity are illustrated in table 5. Statistically significant differences were found between both categories of the operators with regards to the time of rubber dam application and the duration of rubber dam placement $(P<0.05)$.

Table 5. Time and duration of using RD by both groups.

\begin{tabular}{|c|c|c|c|c|}
\hline TIME & Minimum & Mean & Median & Maximum \\
\hline Rubber dam placement (min) \\
\hline Endodontists & 0.5 & 1.10 & 1 & 4.9 \\
\hline GDPs & 2 & 4.28 & 4.5 & 7 \\
\hline Rubber dam presence (min) \\
\hline Endodontists & 10 & 28.12 & 30 & 43 \\
\hline GDPs & 25 & 49.95 & 40 & 120 \\
\hline
\end{tabular}

\section{Discussion}

Dental fear centre stated, "In an era when forums provide resources and the opportunity for the sharing of information, it should be argued that rubber dam usage benefits are not to be underestimated. Well-informed patients can see the logic of isolating a tooth for both clinical and safety reason" [29]. The later was also reported by Webber [30]. This study was designed aiming to obtain the maximum possible information about patient's opinions concerning their experience with the usage of a rubber dam and to examine the influence of various factors. The number of respondents surveyed was 200. The authors are aware that a possible limitation of this study might be the sample size owing to the limited regular use of rubber dam in Libya. In this study, the method used to collect information was constructed in such a way to allow a high response rate than may have been achieved in the similar studies already referred to $[25,26]$. It also compares endodontic specialists with general dental practitioners. As the number of rubber dam regular users is rather limited in Libya [10] and other countries [6,12,13], there is a high discrepancy between the offer of treatment with rubber dam by dentists and the demand of the patients. This finding is really alarming, because rubber dam is considered a standard of dental care [1].

Failure to use rubber dam had been shown to influence the choice of root canal irrigants. Usually chemically active irrigants such as sodium hypochlorite are avoided when rubber dam is not placed, so as the patient would not be affected by its irritant taste. This proved to have a negative impact on the outcome of endodontic treatment. Furthermore, the failure to use a rubber dam may pose a risk of swallowing or aspirating endodontic materials or instruments [20].

Literature search indicated that one of the reasons for the low prevalence of RD use was lack of patient compliance [17]. Nevertheless, in this study; the majority of patients reported the use of $\mathrm{RD}$ as comfortable. A similar proportion of patients also stated their future preference to use RD. In this study, the preference for RD usage in the 
future was significantly associated with the patient acceptance and comfort in the current session. This is in line with other studies $[23,28,31,32]$.

In this survey, it is evident that only a few respondents from either group did not wish to have their endodontic treatment under RD in future appointments, which is in agreement with other studies [33]. The current survey also demonstrated that the majority of patients did not report any negative attitude towards $\mathrm{RD}$, and indeed many liked it and want it to be used further. In Croatia, $58 \%$ of the patients reported comfort while their endodontic treatment was carried out under rubber dam, furthermore $69 \%$ indicated that they would prefer rubber dam to be placed in their next endodontic sessions [22]. Another survey reported a higher proportion of patients whom indicated their comfort while the endodontic treatment was performed under rubber dam $(77 \%)$ and also $86 \%$ of patients would prefer the use of rubber dam in future treatment sessions [28]. In the current study, the proportion of patients with preference of future rubber dam use was quite higher than reported in other studies [22, 23, 28]. The later was in line with a very recent study conducted by Madarati et al [24]. Authors believed that patients' safety was the most attractive advantage for patients towards the application of RD [24].

Another cited reason for not using rubber dam by many dentists is the time needed to place it [16-20]. The amount of time required to place rubber dam is usually overemphasized [20, 22, 33]. Moreover, practitioners are often afraid that patients will not accept the rubber dam $[20,33]$. In the experience of routine rubber dam users, placing rubber dam in regular situations does not necessitate more than a minute or two of extra time. Most patients endure the rubber dam if the dentist/student instruct them. They also report their bear and comfort [22, $23,28]$.

The mean time needed for rubber dam placement by the GDPs in this current study was comparable with other published studies $[11,12,14]$. In addition, it was found that general dental practitioners needed more time for both placement of the rubber dam and also the time required for the whole treatment session compared with endodontists. It could be argued that, the discrepancy between both groups could be related to the experience, training and motivation of endodontists.

Several obstacles for using rubber dam had been highlighted by many authors $[20,22,32]$. Those include the lack of experience, underestimation of its benefits and also the lack of motivation and proper training.

Patient's satisfaction towards endodontic treatment is related to different factors, such as factors related to the patient himself like his health status and the others depending on the nature of the endodontic procedure itself [34].

In the current study only one patient could not finish the treatment session with the rubber dam placed. The patient reported a history of occasionally difficulty in breathing. The patient was referred to a physician for full investigation. The contraindications for using rubber dam had been highlighted by other authors [35], those include asthmatic patients or mouth breather.

In the current study a positive attitude of patients towards the use of rubber dam was reported after the explanation of the benefits of RD placement was performed by their operators. It could be argued that proper explanation by operator encourage the patients positively toward the acceptance of rubber dam. Every effort should be employed by general dental practitioners and endodontists to show the importance of such a mandatory device during endodontic treatment.

\section{Conclusions}

Patients showed a positive attitude towards rubber dam application following proper explanation of the procedure, proper application technique and short treatment time. Operators experience improved patients' compliance.

\section{Recommendation}

Methods to popularize rubber dam amongst general dental practitioners accompanied with educational courses.

\section{Acknowledgements}

Authors would like to thank all patients who participated in this study.

\section{Conflicts of Interest}

The authors declare no conflict of interest.

\section{REFERENCES}

[1] Elderton RJ. A modern approach to use of rubber dam. Dental Practitioner and Dental Record. 1971; 21: 187-193, 226-232, 267-273.

[2] Shashrekha A, Amit Jena, Asim Bikash Maity, Pankaj Panda. Prevelance of rubber dam usage during endodontic procedure: A questionnaire survey. Jou of Clin and Diag Res. 2014, Vol 8 (6) ZCOL-ZCO3.

[3] European Society of Endodontology. Quality guidelines for endodontic treatment: Consensus report of the European Society of Endodontology. Int Endod J.2006; 39: 921-930.

[4] American Association of Endodontists. Guide to Clinical Endodontics. 4th ed. Chicago, IL. 2004, American Association of Endodontists. 
[5] American Academy on Pediatric Dentistry Clinical Affairs Committee-Pulp Therapy subcommittee, American Academy on Pediatric Dentistry. Guideline on pulp therapy for primary and young permanent teeth. 2008-2009; 30: $170-174$

[6] Guidelines for Infection Control. Australian Dental Association. $3^{\text {rd }}$ ed. St Leonards NSW 1590. 2015; Australia.

[7] European Society of Endodontology. Consensus report of the European Society of Endodontology on quality guidelines for endodontic treatment. Int Endod J. 1994; 27: 115-124.

[8] British Endodontic Society. A survey of endodontics in general practice in England. Br Dent J. 1983; 154: 222- 224.

[9] Madarati AA. Why dentists don't use rubber dam during endodontics and how to promote its usage?BMC Oral Health.2016; 16:24.

[10] Orafi, Hamad 2017.Opinions and attitudes of general dental practitioners in Libya towards the use of rubber dam during endodontic treatment. Ain Shams Dent J. 2016; XIX: 35-47.

[11] Kabore WA, Chevalier V, Gnagne-Koffi Y, Ouédraogo CD, Ndiaye D, Faye B. A Survey of Endodontic Practices among Dentists in Burkina Faso. J Contemp Dent Pract. 2017; 18(8): 641-646.

[12] Lin HC, Pai SF, Hsu YY, Chen CS, Kuo ML, Yang SF, et al. Use of rubber dams during root canal treatment in Taiwan. J Formos Med Assoc. 2011; 110: 397-400.

[13] Going RE, Sowinski VJ. Frequency of use of the rubber dam: A survey. J Am Dent Assoc. 1967; 75:158-166.

[14] Koch M, Eriksson HG, Axelsson S, Tegelberg A. Effect of educational intervention on adoption of new endodontic technology by general dental practitioners: A questionnaire survey. Int Endod J. 2009; 42: 313-321.

[15] 15. Savani GM, Sabbah W, Sedgley CM, Whitten B. Current trends in endodontic treatment by general dental practitioners: Report of a United States National Survey. J Endod. 2014; 40: 618-624.

[16] Hill EE, Rubel BS. Do dental educators need to improve their approach to teaching rubber dam use? Journal of Dent Educ. 2008; 72: 1177-1181.

[17] Lynch CD, McConnell RJ. Attitudes and use of rubber dam by Irish general dental practitioners. Int Endod J. 2007; 40: 427-432.

[18] Mala S, Lynch CD, Burke FM, Dummer PMH. Attitudes of final year dental students to the use of rubber dam. Int Endod J. 2009; 42: 632-638.

[19] Whitworth JM, Seccombe GV, Shoker K, Steele JG. Use of rubber dam and irrigant selection in UK general dental practice. Int Endod J. 2000; 33: 435-441.

[20] Ahmad IA. Rubber dam usage for endodontic treatment: a review. Int Endod J.2009; 42(11): 963-972.

[21] Gilbert GH, Riley JL, Eleazer PD, Benjamin PL, Funkhouser E, National Dental PBRN Collaborative Group, et al. Discordance between presumed standard of care and actual clinical practice: The example of rubber dam use during root canal treatment in the national dental practice-based research network. BMJ. 2015; 5: e009779.

[22] Filipovi c J, Juki c S, Mileti c I, Paveli c B, Malci c A, Ani c I. Patient's attitude to rubber dam use. Acta Stomatologica Croatica. 2004; 38: 319-322.

[23] Stewardson DA, McHugh ES. Patients' attitudes to rubber dam. Int Endod J. 2002; 35: 812-819.

[24] Ahmad M, Seema A, Faisal T, Ali E, Aya S, Mohamad B , Muhammad Z. Dental-Dam for Infection Control and Patient Safety during Clinical Endodontic Treatment: Preferences of Dental Patients. Int. J. Environ. Res. Public Health. 2018; 15(9): 2012.

[25] Gergely EJ. Rubber dam acceptance. Br Dent J. 1989; 167 : 249-252.

[26] Jones C, Reid J. Patient and operator attitudes toward rubber dam. Jour of Dent for Child. 1988; 55: 452-454.

[27] Vedavathi B, BV Sreenivasa Murthy, Roopa R Nadig, John V George. Patients' Attitude to Rubber Dam: A Short-term Study. Worl J of Dent. 2011; 2: 167-168.

[28] Kapitan M, Hodacova L, Jagelska J, Kaplan J, Ivancakova R and Sustova Z.The attitude of Czech dental patients to the use of rubber dam. Health Expect. 2015; 18: 1282- 1290.

[29] Dental Fear Central. What is a rubber dam and why would your dentist want to use one? Available at: http:// www.dentalfearcentral.org/faq/rubber-dam/ (accessed Janu ary 2018).

[30] Webber, J. Endodontics: No rubber dam, no root canal. Br Dent J. 2017; 222 (3):142.

[31] Maslamani M, Mitra, AK. Factors associated with patients' satisfaction of rubber dam use during root canal treatment. Ind J of Dent Res. 2018; 29(2): 144- 149.

[32] Soldani F, Foley J. An assessment of rubber dam usage amongst specialists in paediatric dentistry practising within the UK. Internt J of Paed Dent. 2007; 17: 50-56.

[33] Marshall K, Page J. The use of rubber dam in the UK. A survey. Br Dent J.1990; 10: 169(9): 286-291.

[34] Alshammari Y, Almuthin M, Alarajah A, Barri GM, Alshammari H, Alshahrani S. Patients Satisfaction after Endodontic Treatment in Saudi Arabia. The Egyptian Jour of Hospt Med. 2018; 70 (5): 791- 795.

[35] Liu P, McGrath C, Cheung GSQuality of life and psychological wellbeing among endodontic patients: acase control study. Aust Dent J. 2012; 57(4): 493-497. 